\title{
Rootstock Effects on the Flowering of 'Delicious' Apple. I. Bud Development
}

\author{
Peter M Hirst ${ }^{1}$ and David C Ferree \\ Ohio Agricultural Research and Development Center, The Ohio State University, Wooster, OH 44691
}

Additional index words. Malus domestica, appendages, growth, apical dome, spur quality

\begin{abstract}
Floral development was studied in buds of 'Starkspur Supreme Delicious' apple trees growing on B.9, M.26 EMLA, M.7 EMLA, P.18, and seedling rootstocks. In each of 3 years, buds were sampled from the previous years growth at intervals throughout the growing season and dissected to determine whether the apex was domed, indicating the start of floral development. Number of bud scales and true leaves increased during the early part of the growing season, but remained fairly constant beyond 70 days after full bloom. The type of rootstock did not affect the number of bud scales or transition leaves, and effects on true leaf numbers were small and inconsistent. Final bract number per floral bud was similarly unaffected by rootstock. The proportion of buds in which flowers were formed was influenced by rootstock in only one year of the study, which was characterized by high temperatures and low rainfall over the period of flower formation. Bracts were observed only in floral buds, and became visible after doming of bud apices had occurred. Flowers were formed during the first $\mathbf{2 0}$ days in August, regardless of rootstock or year. The appendage number of vegetative buds was constant from 70 days after full bloom until the end of the growing season, but the number of appendages in floral buds increased due to the continued production of bracts. The critical bud appendage number for 'Starkspur Supreme Delicious' before flower formation was 20, and was stable among rootstocks and years. Buds with diameters above $3.1 \mathrm{~mm}$ were generally floral, but on this basis only $65 \%$ of buds could be correctly classified. Spur leaf number, spur leaf area, and spur leaf dry weight were not good predictors of floral formation within the spur bud.
\end{abstract}

The principal fruiting units in apple are spurs, which may be classified as short shoots. The terminal bud of a spur may be either vegetative containing only leaves, or reproductive. Reproductive buds of apple are mixed buds that produce both flowers and leaves. Bijhouwer (1924) described an apple fruit bud as typically bearing 21 leaf formations consisting of 9 budscales, 3 transition leaves, 6 true leaves, and 3 bracts.

The first morphological indication of the transition from vegetative to reproductive development in apple is a change in the shape of the apex from flattened to domed (Abbott, 1977; Fulford, 1966b; Luckwill and Silva, 1979). Doming of the apex was classified as induction by Luckwill (1974), but the definition of Buban and Faust (1982) may be more appropriate where induction only included the process whereby the genes controlling flower bud production cease to be repressed. Subsequent events are development of the growing point (visually manifest by doming of the apex), production of flower primordia and differentiation of flower parts.

The number of appendages required before flower formation is influenced by cultivar and ranged from 16 for 'Golden Delicious' (Luckwill and Silva, 1979) to 20 for 'Cox's Orange Pippin' (Abbott, 1977). Similarly, the number of appendages before flower parts were evident ranged from 18 for 'Baldwin' to 22 for 'Early McIntosh' (McLaughlin and Greene, 1991). The time at which the first visible sign of flower formation becomes evident can also be influenced by cultivar. In South Africa, the time fruit bud differentiation was first noted varied by up to a month among cultivars in a given year (Micklem, 1938). Other work suggests that cultivar may influence the type of appendage present in flower buds (McLaughlin and Greene, 199 1).

Received for publication 9 Feb. 1995. Accepted for publication 14 June 1995 Salaries and research support provided by state and federal funds appropriated to the Ohio Agricultural Research and Development Center, The Ohio State Univ. Peter M. Hirts acknowledges additional support from The Horticulture and Food Research Institute of New Zealand Ltd. The cost of publishing this paper was defrayed in part by the payment of page charges. Under postal regulations, this paper therefore must be hereby marked advertisement solely to indicate this fact. 'Current address: The Horticulture and Food Research Institute of New Zealand Ltd., Private Bag 1401, Havelock North, New Zealand.
A negative relationship between vegetative growth and flower formation is commonly recognized, and factors that induce early cessation of shoot growth often lead to increased flower bud formation (Forshey, 1989; Luckwill, 1970). Many factors have been shown to shift the balance between vegetative growth and flower initiation, but perhaps the most striking are various plant growth regulators (Jones, et al., 1989; Luckwill and Silva, 1979; Volz and Knight, 1986), and rootstocks (Luckwill, 1970; NC-140, 1990; Swarbrick, 1929). In these studies it has been suggested that it was the early termination of shoot growth that led to increased flower initiation. Others have also noted that flower initiation occurs only after shoot growth has ceased (Abbott, 1970; Abdulkadyrov et al., 1972).

There is no question that rootstocks influence flowering in apple (Ferree, 1976; Maggs, 1955; NC-140,1990). In a study with 'Delicious' growing on 17 rootstocks, Hirst and Ferree (1995) found that flower density (the number of flowers per meter of shoot length) was closely related to the proportion of spurs that formed flowers, but was unaffected by spur density. They concluded that rootstocks affect flowering not by increasing the spur population, but by increasing the number of flower clusters for a given number of spurs.

This study was conducted to investigate the effect of rootstocks on the development of spur buds. The specific objectives were to determine whether rootstocks influence 1) the critical appendage number occurring within the bud before flower development, 2) the time of flower bud differentiation as indicated by doming of the apex, and 3) the type of bud appendage present in the bud. In addition, we examined the influence of rootstocks on the relationship between vegetative growth and bud development.

\section{Materials and Methods}

Trees of 'Starkspur Supreme Delicious' apple were planted; near Wooster, Ohio, in 1984 at a spacing of $3.5 \times 5.5 \mathrm{~m}$ as part of a rootstock evaluation program (NC-140,1990). Of the 17 rootstocks represented in this planting, B.9, M.26 EMLA, M.7 EMLA, P. 18 and seedling were chosen for detailed study of their effects on bud 
development. These rootstocks were selected to represent a wide range of tree size, and after 10 years growth, tree size as a percentage of seedling was B.9 29\%, M.26 EMLA 48\%, M.7 EMLA 62\%, and P. 18 92\% (Hirst and Ferree, 1995). Trees were planted in a randomized complete block design-with 10 single tree replications. 'Macspur' and 'Golden Delicious' trees were included in the planting for pollination purposes, and standard management practices were followed. No irrigation was provided to the trees. Growth and yield characteristics of these trees have been previously reported (Hirst and Ferree, 1995).

During 1991 and 1992, buds were sampled from the previous year's growth from about 70 days after full bloom (DAFB) until late in the growing season. Similar buds were sampled in 1993 from 20 to 172 DAFB. Flowers are initiated in apple buds the year before their emergence. To study the formation of spur flowers, first borne on 2-year-old wood, buds must be sampled from 1-yearold wood. On each sampling date, either three (199 1) or two (1992, 1993) spurs were removed from branches located in well illuminated positions around the periphery of each tree. To minimize the inhibiting effects of fruit on flower initiation, buds were collected from branches that did not carry fruit on the 1 -year-old section. The leaf number, leaf area, and leaf dry weight of sampled spurs was determined. Following measurement of their diameters, buds were stored in a formalin, 70\% ethanol, acetic acid solution (10:50:5, by volume) (McLaughlin and Greene, 1991). Buds from 8 (1991, 1992) or 10 (1993) replications were dissected with a dissecting microscope (SZ-60; Olympus), and the remainder of the buds kept for photographic purposes. During dissection of the buds, appendages were counted and classified as bud scales, transition leaves, true leaves or bracts. In addition, the meristem was characterized as flattened, indicating a vegetative state (Fig. 1A) or domed indicating that flower formation had begun (Figs. $1 \mathrm{~B}$ and C). Buds were classified as floral as soon as doming of the apex was observed (Fig. 1B). The critical bud appendage numberjust before doming of the apex was determined for each rootstock by linear discriminant analysis.

To determine the relationships between bud development and the rate and duration of shoot growth, five shoots around the periphery of each tree were selected in 1992 and 1993. The length and leaf number of these tagged shoots were measured at intervals from about 20 DAFB until late in the growing season when all shoot growth had ceased.

Data were analyzed using analysis of variance for the separation of means. Linear discriminant analysis was used for prediction of critical bud appendage numbers and chi-square was used for analysis of proportion data (Minitab 1993).

\section{Results}

Bud development The number of bud scales was not affected by rootstock, therefore data from all rootstocks were pooled. During all 3 years, the increase in bud scales was curvilinear, indicating more rapid production of bud scales earlier within a season (Fig. 2). Over the period from 25 to 75 DAFB, about two additional bud scales were produced in 1993. The number of transition leaves was not affected by eitherrootstock or sampling date (data not presented). The number of transition leaves over these rootstocks ranged from 2.0 to 2.2 in 1991, 1.9 to 2.2 in 1992, and 2.2 to 2.4 in 1993.
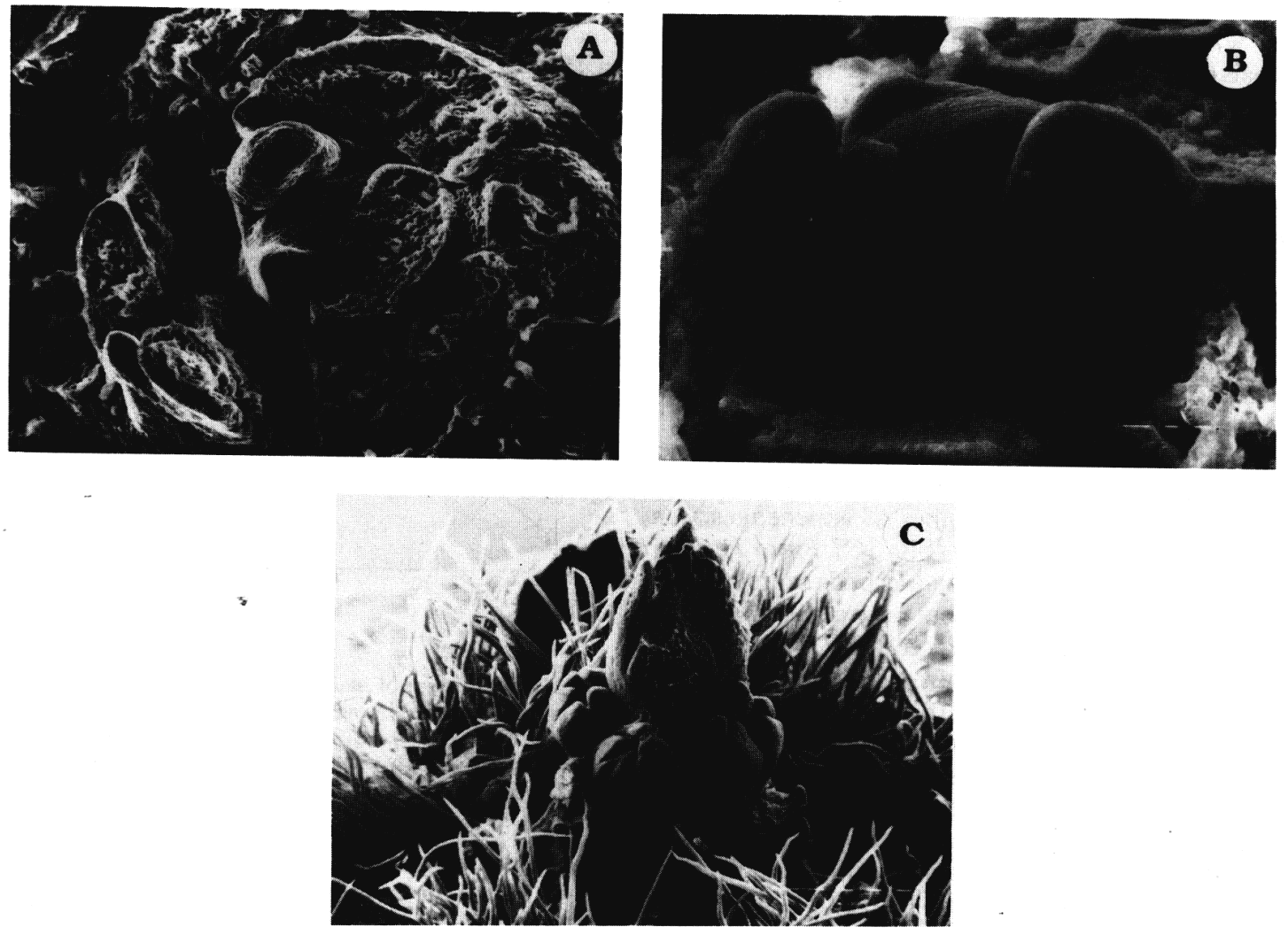

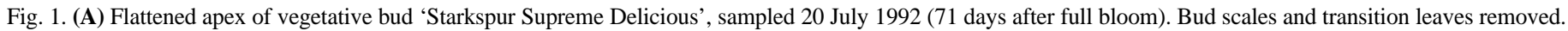
Two small true leaves remain. Left bar $=10 \mu \mathrm{m}$. (B) Apical meristem of 'Starkspur Supreme delicious', sampled 7 Aug. 1992 (89 days after full bloom). Doming of apex indicates transition to a floral status. Bud scales and transition leaves removed. Three true leaves remain. Left bar $=10$ pm. $(\mathbf{C})$ Floral meristem of 'Starkspur Supreme Delicious', sampled 25 Sept. 1992 (138 days after full bloom). Differentiation of the apex has occurred and the king flower and three lateral flowers are visible, with sepal primordia. Bud scales, transition leaves true leaves and bracts removed. Left bar $=10 \mu \mathrm{m}$. 
Rootstock affected the number of true leaves in the bud in 1992 and 1993, but the differences were small and inconsistent between years (data not presented). The range of values among rootstocks for true leaves was 7.1 to $7.3,6.6$ to 6.9 , and 6.2 to 6.5 in 1991,1992 and 1993 respectively. In 1991 and 1992, the number of true leaves was generally constant over the growing season. In 1993 however, true leaf number increased with time, especially during the early part of the season. In general, the number of true leaves showed similar trends as the number of bud scales, and increased by three over the course of the 1993 growing season, and two of these were added over the first 70 days following bloom (data not shown).

Bracts were observed only in buds where doming of the apex was already evident and were absent in vegetative buds. Both the timing of initiation of bract production, and the final number of bracts produced was unaffected by either rootstock or year (data not presented) During each year the number of bracts in floral buds increased rapidly from 0 at 90 DAFB to about 10 on the last sampling date. The plastochron for bracts (number of days required for the production of one additional bract) is the reciprocal of the slope of the time course lines of the number of bracts per flowering bud. Across all rootstocks, yearly means for the bract plastochron were 6.7, 4.4, and 6.5 days in 1991, 1992, and 1993, respectively. Although there was a tendency for the bract plastochron to be shorter in 1992 when large numbers of flowers were formed, it was about the same in 1991 and 1993 when flowers were formed in moderate and low numbers of buds respectively.

In 1991, the total number of bud appendages (bud scales, transition leaves, true leaves, and bracts) at 70 DAFB was about 16 for all rootstocks (Fig. 3A). In all cases the number of appendages increased over the period of study, with most of the increase occurring from 90 to 120 DAFB. Rootstocks separated into 2 groups on the basis of their final appendage number $(P \geq 0.05)$ with trees growing on B.9 and M.7 EMLA having more appendages than those on M.26 EMLA, P. 18, or seedling rootstocks (23.1 and 19.9 appendages respectively, Fig. 3A).

Until 90 DAFB, buds from trees on all rootstocks had about the same appendage number in 1992 as in the same period during the previous year (Fig. 3B). After 90 DAFB in 1992, a rapid increase in appendage number was observed for all trees (Fig. 3B). Total appendage numbers continued to increase until the last sampling date 138 DAFB (Fig. 3B). There was no rootstock effect on final appendage number in 1992, with 26 to 28 appendages present in buds from trees on all rootstocks.

Buds were sampled earlier in 1993 than in previous years to investigate the effects of rootstock on bud development soon after flowering. An increase in the total number of appendages was observed over the period 22 to 71 DAFB (Fig. 3C). From 71 to 95 DAFB buds had similar appendage numbers as buds sampled over the same period during the last 2 years, but only a slight increase took place over the remainder of the growing season. Final appendage numbers were higher in buds from trees on B.9 than in similar buds from trees on M.26 EMLA, P.18, or seedling rootstocks.

Although flower formation was first observed in two buds on 26 July 1991 (85 DAFB), in general doming did not occur in 1991 until 1 Aug. (91 DAFB). The proportion of sampled bracts flowering reached a maximum at 109 DAFB after which a plateau was attained (Fig. 4A). Distributions were net significantly different from $100 \%$ vegetative buds until 99 DAFB $(P \geq 0.05)$. Significant increases in the proportion of floral buds only occurred over the period from 91 to 109 DAFB (that is, 1-19 Aug.). As with the total appendage data, rootstocks appeared to fall into two groups, with flowers evident in about $60 \%$ of the buds sampled from trees on B.9 and M.7 EMLA rootstocks, whereas only $20 \%$ to $40 \%$ of the buds from trees on M.26 EMLA, P.18, or seedling rootstocks formed flowers $(P \geq 0.01$, Fig. 4A).

In 1992, the first flowers were observed in buds sampled on 7 Aug. (89 DAFB), but significant increases in the proportions of buds in which flowers formed were not detected until 25 Aug. (107 DAFB) (Fig. 4B). Flowers were observed in virtually all buds sampled across all rootstocks at $107 \mathrm{DAFB}$, and this remained true until the last buds were sampled 138 DAFB.

Very few flowers were formed during 1993, and on none of the sampling dates was the proportion of floral buds significantly different from zero (Fig. 4C). The first flowers were observed in buds on 9 August (95 DAFB), but the proportions of flowering buds were variable due to low flower numbers. For example, of the 100 buds examined across the 5 rootstocks on each sampling date, the maximum number of flowers observed was 10 at 124 DAFB and of these, 6 were found in buds from trees growing on B.9 rootstock (Fig. 4C).

The number of bud appendages differed in vegetative compared with flowering buds, especially in the latter stages of the growing seasons (Figs. 5 A-C). There was no consistent rootstock effect on the rate of increase in appendages in any year (Figs. 5 A-C), therefore, data for all rootstocks were pooled. Bud development before 67 DAFB was only measured in 1993, and for all rootstocks the number of appendages in vegetative buds increased over the period 22 to 71 DAFB (Fig. 5C) from 12 up to 16 appendages. From about 75 DAFB until the end of the respective growing seasons, vegetative buds added appendages at a slower rate, increasing from about 16 up to 17 appendages over this period (Figs. 5 A-C). Doming of the apex first appears from 85 to 95 DAFB ( 1991 to 1993, respectively), and the number of appendages was initially similar to that in vegetative buds. Across all rootstocks, the plastochron for vegetative buds was 75,43 , and 26 days in 1991, 1992, and 1993, respectively. The short plastochron in 1993 was an artifact of the earlier sampling date than in previous

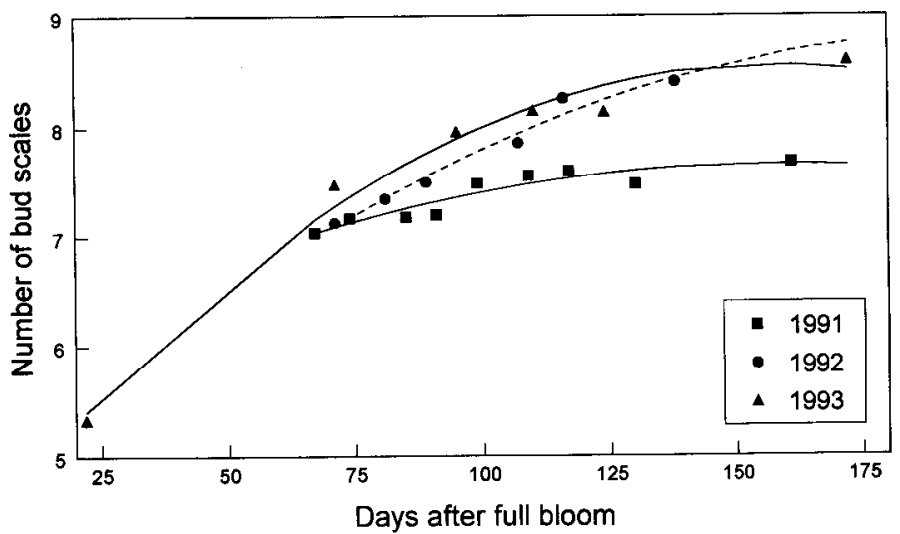

Fig. 2. Development of bud scales in 1-year-old vegetative buds of 'Starkspur Supreme Delicious' in each of 3 years. Each point is the mean of trees growing on B.9, M.26 EMLA, M.7 EMLA, P.18, and seedling rootstocks (1991, n= 120; 1992, $n=80 ; 1993, n=100)$. Full bloom occurred on 2 May 1991, 10 May 1992, and 6 May 1993.

years since when data from this date were omitted, the plastochron was 60 days. Floral buds, on the other hand, had plastochrons of 8 , 5 , and 7 days in 1991; 1992, and 1993, respectively.

The critical number of appendages before doming of the apex was 20, and was not affected by either rootstock or year (Table 1). In each year, linear discriminant models derived for each rootstock were used to predict doming of the apex based on the total bud 

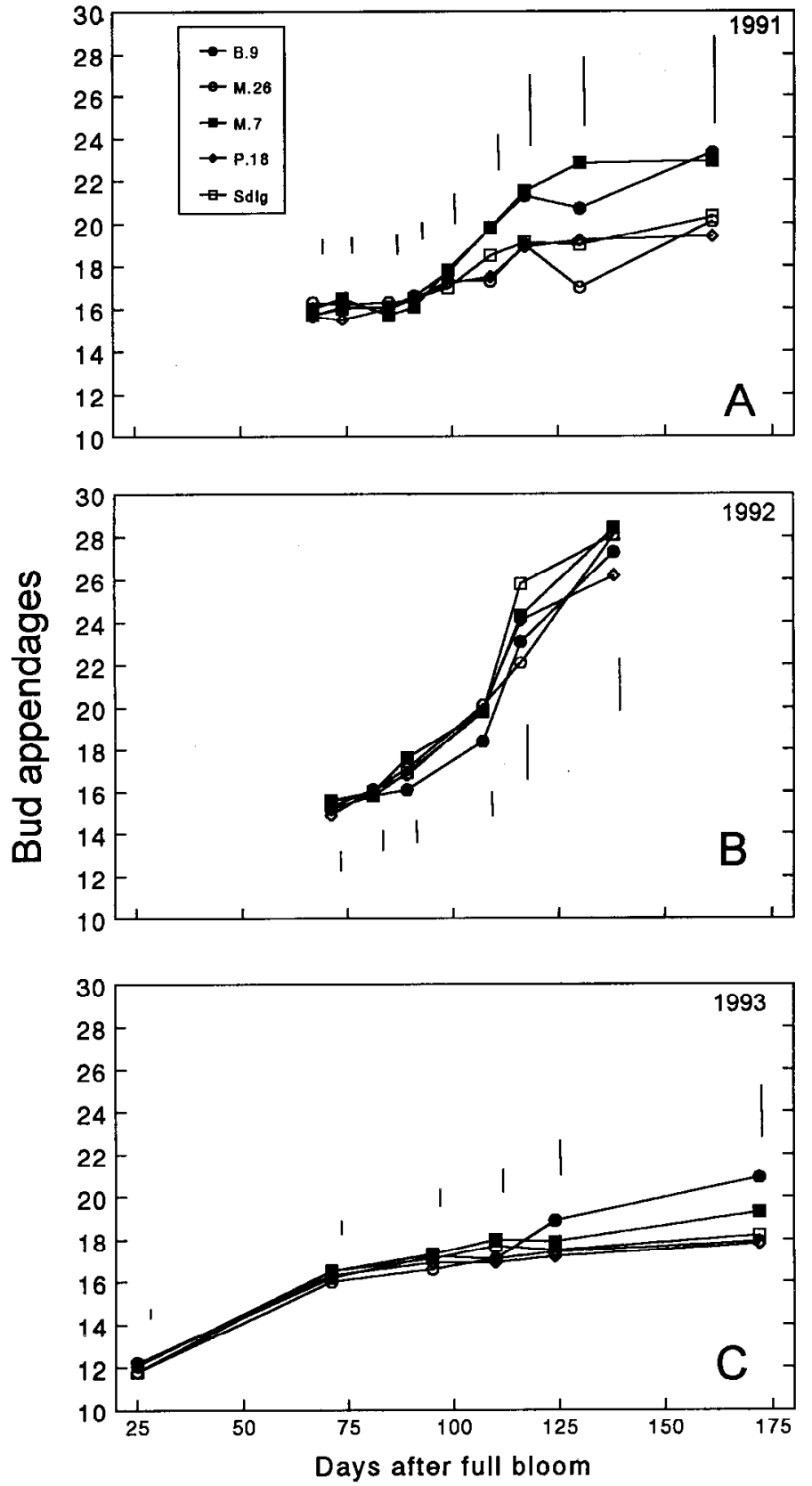

Fig. 3. Total bud appendages (bud scales plus transition leaves plus true leaves plus bracts) of 'Starkspur Supreme Delicious' growing on five rootstocks. (A) 1991, fullbloom = 2 May 1991, $\mathrm{n}=24$. (B) 1992, full bloom $=10$ May, $\mathrm{n}=16$. (C) 1993, full bloom $=6$ May, $\mathrm{n}=20$. Bars indicate $\operatorname{LSD}(P=0.05)$.

appendage number. These models classified most buds correctly, with more than $84 \%$ correct in all cases, and in many instances this was-in excess of $90 \%$. A single model derived using data from all rootstocks in all years predicted $94 \%$ of all buds correctly and determined a critical appendage number of 20 (Table 1). Since bracts were only observed in buds with domed apices, it may be argued that the critical appendage number before doming should be based on the numbers of bud scales, transition leaves, and true leaves only. This basis was not as reliable a's total appendage number for predicting doming, but enabled correct classifications to be made on about $70 \%$ of buds (data not presented).

Spur quality. Buds with apparent doming consistently had larger diameters, and trends of higher leaf area per spur, leaf dry weight per spur, and higher SLW (Table 2). Similar trends were evident in 1991 and 1992, with few interactions observed in any

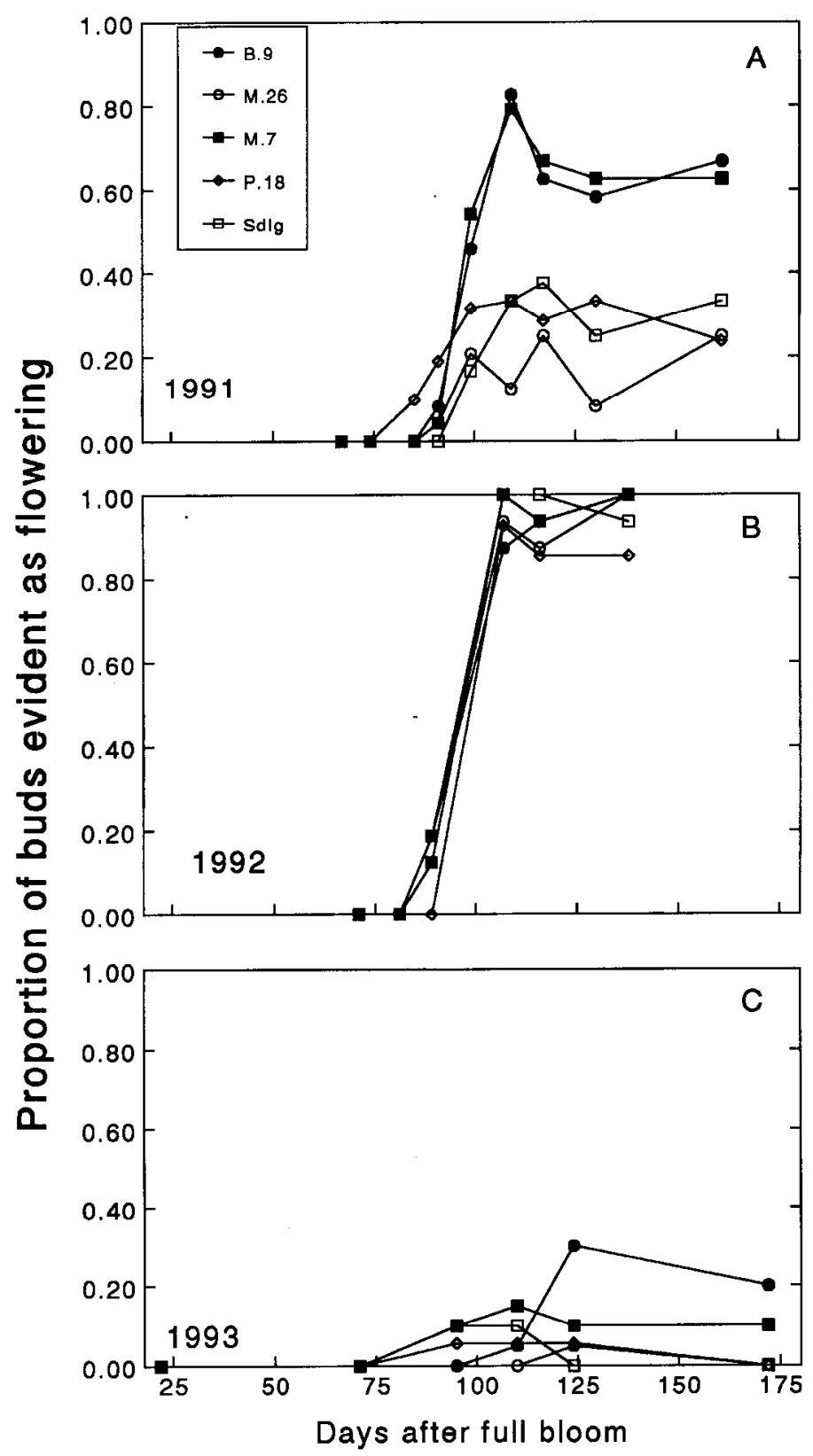

Fig. 4. Proportion of sampled buds in which doming of the apex, indicating the first stages of floral development, was evident in trees of 'Starkspur Supreme Delicious' growing on five rootstocks. (A) 1991, full bloom = 2 May 1991, $\mathrm{n}=$ 24. (B) 1992, full bloom $=10$ May, $n=16$. (C) 1993, full bloom $=6$ May, $n=20$.

year (data not presented). Few interactions were observed. The diameter where buds formed flowers was estimated using linear discriminant analysis in a similar manner as that by which critical appendage numbers were calculated. Flowers tended to appear once buds were about $3.1 \mathrm{~mm}$ in diameter, and this was constant among rootstocks and years (Table 3 ). From bud diameters, it was possible to correctly predict the floral status of about $65 \%$ of the sampled buds. In all years, bud diameters were related with both total appendage numbers and the number of bud scales, which appeared to be the largest sized appendage type present in the bud. These relationships however, were weak and explained $<25 \%$ of the observed variation. Over the course of each growing season, the number of leaves per spur tended to decrease slightly, probably due to abscission of the small primary spur leaves (Table 2). Despite this, the leaf area per spur was constant over time within 

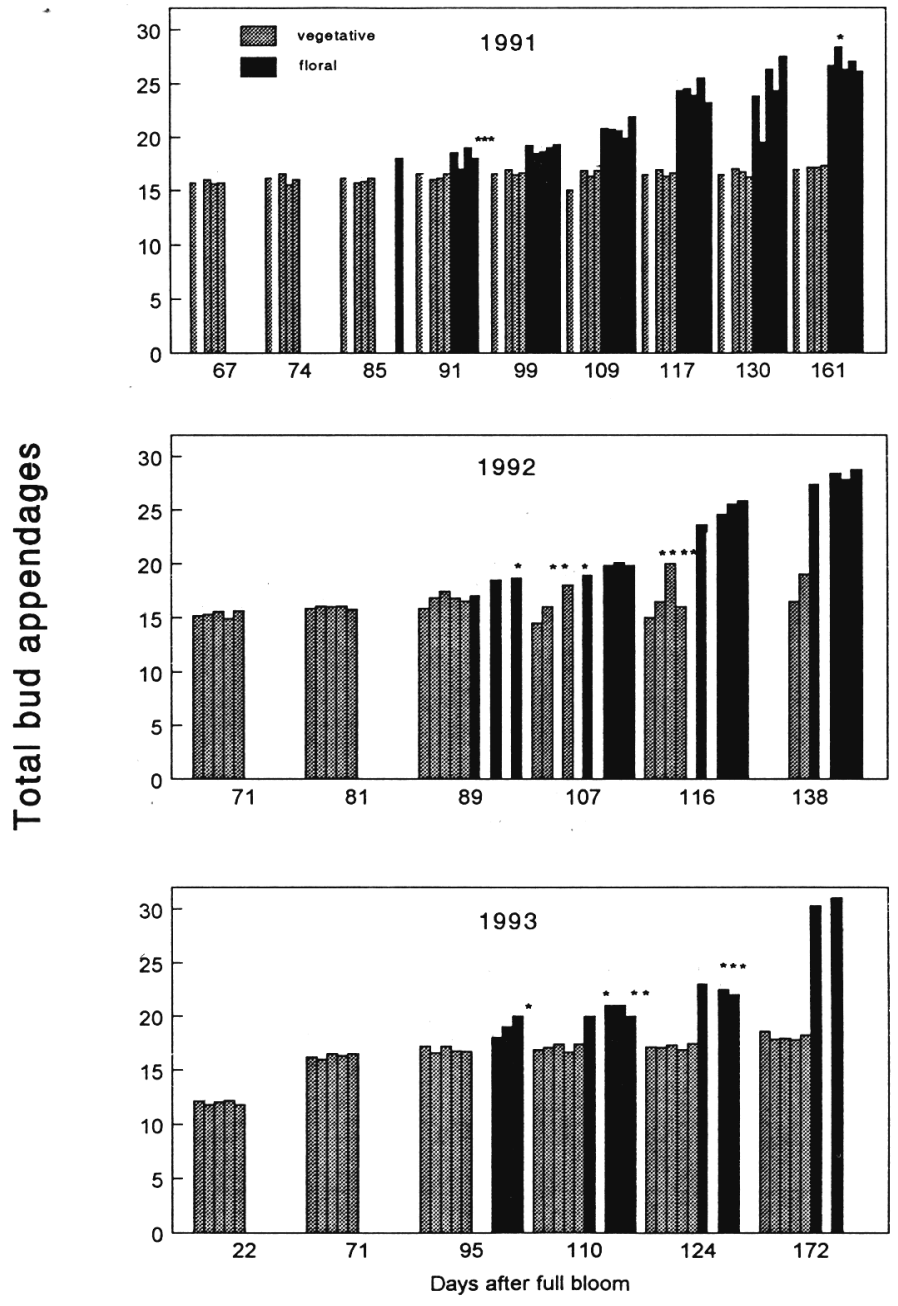

Fig. 5. Total bud appendage number of vegetative and floral buds of 'Starkspur Supreme Delicious' growing on five rootstocks. Bars within each series (from left to right) represent buds from B.9, M.26 EMLA, M.7 EMLA, P.18, and seedling rootstocks, respectively. (A) 1991, full bloom $=2$ May. (B) 1992, full bloom = 10 May. (C) 1993, full bloom = 6 May. *Observations composed of 2 values.

each season. The dry weight of leaves per spur increased during the 1991 and 1993 seasons and higher leaf dry weights per unit leaf area were consistently found in the latter parts of each growing season. Spurs from trees growing on B.9 and M.26 EMLA rootstocks tended to have lower leaf areas but higher specific leaf weights (SLW, leaf dry weight per unit leaf area). Leaf number per spur, leaf area per spur and leaf dry weight per spur were not good predictors of apical doming, and generally only allowed the correct classification of about $50 \%$ of the buds sampled.

Shoot growth. During 1992, shoots on all rootstocks grew strongly for about 40 days after full bloom, then extension growth virtually ceased. Over this period, maximum shoot growth rates were observed on trees growing on seedling rootstocks $(8 \mathrm{~mm} \cdot$ day $\left.{ }^{1}\right)$ and the slowest growth was with trees on M.26 EMLA rootstock at $5 \mathrm{~mm} \cdot \mathrm{day}^{-1}$ (Fig. $6 \mathrm{~A}$ and B). Shoot growth of trees growing on other rootstocks was intermediate. No rootstock effect on the time of cessation of shoot growth was evident, with only minor amounts of growth occurring after 40 DAFB, which corresponded to 18 June. Patterns of shoot growth observed during 1993 were broadly similar to those during the previous year (Fig. $6 \mathrm{~A}$ and $\mathrm{B}$ ). The shoot growth rate in 1993 demonstrated a similar periodicity as in 1992, with a marked reduction at 40 DAFB, although the cessation of shoot growth was not as abrupt as during the previous year. Both shoot growth rate and total shoot length were more variable in 1993 compared with 1992, and no significant rootstock effects were apparent. Final shoot lengths were similar between years, although in 1993 this was achieved via a lower shoot growth rate and longer duration of growth compared with the previous year. For both years, leaf numbers per shoot varied in proportion with shoot length (data not shown).

\section{Discussion}

Rapid increases in the number of appendages within the bud has been shown to occur soon after flowering of apple, but the rate of appendage production decreases later in the season (Fulford, 1965, 1966a). In the present study, buds were sampled from mid to late season to study changes in the bud likely to be immediately related to flower formation. Marked increases in both the number of bud scales and true leaves were apparent early in the 1993 season when sampling began 22 DAFB, but from 70 to 180 DAFB increases were minor in magnitude (Fig. 2). The total appendage number of vegetative buds increased during the early part of the season, but increased at a much slower rate after 70 DAFB (Fig. 6 A-C). In floral buds however, appendage numbers continued to increase due to the sustained production of bracts (Fig. 5 A-C).

The plastochron of bud appendages was much shorter in floral buds than vegetative buds over the period from 70 to 180 DAFB due to bract production (Fig. $5 \mathrm{~A}-\mathrm{C}$ ) that is consistent with previous reports (Fulford, 1965, 1966b). In the present study, rootstocks had no consistent effect on the time of initiation of bract production or on the subsequent rate of production. In examining buds from 'Laxton's Superb' and 'Miller's Seedling', Fulford (1965) found no difference in the plastochron of these cultivars and concluded that the mecha-

Table 1. Critical bud appendage number before doming of the bud apex as predicted by linear discriminant analysis for trees of 'Starkspur Supreme Delicious', and the proportion of buds correctly classified as either vegetative or floral by these predictive models.

\begin{tabular}{|c|c|c|c|c|c|c|c|c|}
\hline \multirow[b]{2}{*}{ Rootstock } & \multicolumn{2}{|c|}{1991} & \multicolumn{2}{|c|}{1992} & \multicolumn{2}{|c|}{1993} & \multicolumn{2}{|c|}{ All years } \\
\hline & $\begin{array}{c}\text { Appendage } \\
\text { no. }\end{array}$ & $\begin{array}{c}\% \\
\text { Correct }\end{array}$ & $\begin{array}{c}\text { Appendage } \\
\text { no. }\end{array}$ & $\begin{array}{c}\% \\
\text { Correct }\end{array}$ & $\begin{array}{c}\text { Appendage } \\
\text { no. }\end{array}$ & $\begin{array}{c}\% \\
\text { Correct }\end{array}$ & $\begin{array}{c}\text { Appendage } \\
\text { no. }\end{array}$ & $\begin{array}{c}\% \\
\text { Correct }\end{array}$ \\
\hline B.9 & 19.6 & 94 & 19.3 & 84 & 20.8 & 96 & 19.6 & 92 \\
\hline M.26 EMLA & 19.8 & 95 & 19.8 & 91 & --- & --- & 19.9 & 96 \\
\hline M.7 EMLA & 19.7 & 92 & 20.2 & 85 & 19.6 & 98 & 19.9 & 94 \\
\hline P.18 & 19.1 & 93 & 20.2 & 89 & $18.4^{z}$ & 95 & 19.6 & 95 \\
\hline Seedling & 20.2 & 97 & 20.2 & 84 & $18.2^{z}$ & 89 & 20.1 . & 94 \\
\hline All rootstocks & 19.7 & 95 & 19.9 & 91 & 19.7 & 97 & 19.8 & 94 \\
\hline
\end{tabular}

${ }^{2}$ Based on $<5$ floral buds 
nism controlling the production of primordia was similar. The plastochron for flower buds found in this study was 5 to 8 days that relates very closely to the 7 days found by Fulford (1965), especially when considering that these studies were carried out with different cultivars growing under widely different enviromnental conditions and cultural management regimes.

In contrast with the good agreement for floral spurs, the plastochron of vegetative spurs differed greatly [43 to 75 days in our study compared with 18 days found by Fulford, (1965)]. This discrepancy may be due to the period of measurement. In 1993 spurs were sampled earlier than during the previous 2 years and the number of appendages in vegetative buds increased from 12 at 22 DAFB to 16 at 71 DAFB, after which further increases were very slight (Fig. 5C). Previous work has shown an increase in the number of bud appendages up until August (equivalent to about 90 DAFB) followed by a plateau (Fulford, 1965, 1966a). The production of primordia by vegetative and floral buds is not influenced by cultivar (Fulford, 1965; McLaughlin and Greene, 1991). From the present study, it may be concluded that the mechanism is unaffected by rootstock, suggesting that the plastochron of both vegetative and floral buds may be determined at a species level.

The critical appendage number demonstrated a high degree of stability among rootstocks and years (Table 1), indicating that this is a characteristic inherent to the cultivar. Previous work has determined the critical appendage number either visually from graphs (Luckwill and Silva, 1979), by calculating the mean node number of floral buds (Abbott, 1977), or by calculating the mean appendage number before sepal formation (McLaughlin and Greene, 1991). In this study, discriminant analysis was used to determine that the critical appendage number before apical doming was 20 for 'Starkspur Supreme Delicious', and enabled 94\% of all buds to be classified correctly as either vegetative or floral. In contrast, from the data presented in Figs. 5 A-C, it would appear that the critical appendage number is 16 to 17 , but this is based on means of relatively small numbers of buds. The overall discriminant analysis model, however, is based on individual bud data from the 2100 buds sampled across all rootstocks and for all years. Discriminant analysis offers the advantages of precision as well as prediction of the appendage number that separates vegetative from floral buds. When the critical appendage number was calculated using the sum of the numbers of bud scales, transition leaves and true leaves (omitting bract number), rootstock had no influence but the critical number varied among years. In the year of the highest degree of flower formation (1992), this critical value was lowest (16.6), whereas when few flowers were formed (1993), the critical value was greatest. In floral buds, bract production begins and suppresses the development of further leaves within the bud (Fulford, 1965) therefore when a higher proportion of flower buds are formed, fewer true leaves would be expected to be produced.

Apical doming is the first visible sign of flower formation (Luckwill and Silva, 1979) and generally occurred between 85 and 109 DAFB, which corresponds to 26 July to 19 Aug. (Fig. 4 A-C). Flower bud

Table 2. Effect of time during the growing season [days after full bloom, (DAFB)] rootstock

(RS), and vegetative/floral status of the bud apex on spur quality variables during 1993.

\begin{tabular}{lccccc}
\hline \hline DAFB & Diam & Leaf no. & Leaf area & Dry wt & SLW \\
\hline 22 & $2.06 \mathrm{a}^{\mathrm{z}}$ & $6.6 \mathrm{~b}$ & 55.1 & $0.400 \mathrm{a}$ & $7.18 \mathrm{a}$ \\
71 & $2.90 \mathrm{c}$ & $6.6 \mathrm{~b}$ & 59.5 & $0.587 \mathrm{~b}$ & $9.87 \mathrm{~b}$ \\
95 & $2.75 \mathrm{~b}$ & $6.2 \mathrm{a}$ & 56.0 & $0.577 \mathrm{~b}$ & $10.28 \mathrm{c}$ \\
110 & $3.17 \mathrm{e}$ & $6.1 \mathrm{a}$ & 58.7 & $0.587 \mathrm{~b}$ & $10.02 \mathrm{~b}$ \\
124 & $3.06 \mathrm{~d}$ & $6.0 \mathrm{a}$ & 56.4 & $0.598 \mathrm{~b}$ & $10.62 \mathrm{~d}$ \\
172 & $3.32 \mathrm{f}$ & --- & --- & -- & -- \\
Rootstock & & & & & \\
B.9 & 2.87 & 6.3 & $51.3 \mathrm{a}$ & $0.498 \mathrm{a}$ & 9.74 \\
M.26 EMLA & 2.81 & 6.3 & $55.3 \mathrm{a}$ & $0.540 \mathrm{ab}$ & 9.72 \\
M.7 EMLA & 2.88 & 6.3 & $55.9 \mathrm{a}$ & $0.545 \mathrm{ab}$ & 9.71 \\
P.18 & 2.90 & 6.2 & $62.3 \mathrm{~b}$ & $0.584 \mathrm{~b}$ & 9.32 \\
Seedling & 2.92 & 6.4 & $61.9 \mathrm{~b}$ & $0.585 \mathrm{~b}$ & 9.44 \\
Vegetative/floral apex & & & & & \\
Veg & $2.86 \mathrm{a}$ & 6.3 & 57.1 & $0.546 \mathrm{a}$ & $9.54 \mathrm{a}$ \\
Flwr & $3.31 \mathrm{~b}$ & 6.5 & 60.2 & $0.639 \mathrm{~b}$ & $10.70 \mathrm{~b}$ \\
RS $\times$ DAFB & $* *$ & NS & NS & NS & NS \\
RS $\times$ vẹg/floral & NS & NS & $*$ & NS & NS \\
\hline
\end{tabular}

${ }^{2}$ Values followed by different letters are significantly different at $P 0.05$

ss,$* * *$ Nonsignificant or significant at $P 0.05$ or 0.01 respectively

Table 3. Bud diameter delineating vegetative and floral buds and the proportion of buds correctly classified by linear discriminant analysis.

\begin{tabular}{|c|c|c|c|c|c|c|c|c|}
\hline \multirow[b]{2}{*}{ Rootstock } & \multicolumn{2}{|c|}{1991} & \multicolumn{2}{|c|}{1992} & \multicolumn{2}{|c|}{1993} & \multicolumn{2}{|c|}{ All years } \\
\hline & $\begin{array}{c}\text { Appendage } \\
\text { no. }\end{array}$ & $\stackrel{\%}{\%}$ & $\begin{array}{c}\text { Appendage } \\
\text { no. }\end{array}$ & $\begin{array}{c}\% \\
\text { Correct }\end{array}$ & $\begin{array}{c}\text { Appendage } \\
\text { no. }\end{array}$ & $\begin{array}{c}\% \\
\text { Correct }\end{array}$ & $\begin{array}{c}\text { Appendage } \\
\text { no. }\end{array}$ & $\begin{array}{c}\% \\
\text { Correct }\end{array}$ \\
\hline$\overline{B .9}$ & 3.00 & 64 & 2.94 & 72 & 3.12 & 73 & 3.00 & 67 \\
\hline M.26EMLA & 3.12 & 79 & 3.12 & 68 & ---- & --- & 3.09 & 68 \\
\hline M.7EMLA & 3.01 & 50 & 3.24 & 63 & 3.06 & 60 & 3.11 & 61 \\
\hline P.18 & 3.08 & 71 & 3.24 & 70 & 3.15 & 66 & 3.15 & 67 \\
\hline Seedling & 3.22 & 71 & 3.14 & 69 & 2.99 & 52 & 3.13 & 64 \\
\hline All rootstocks & 3.09 & 71 & 3.14 & 65 & 3.08 & 64 & 3.09 & 66 \\
\hline
\end{tabular}



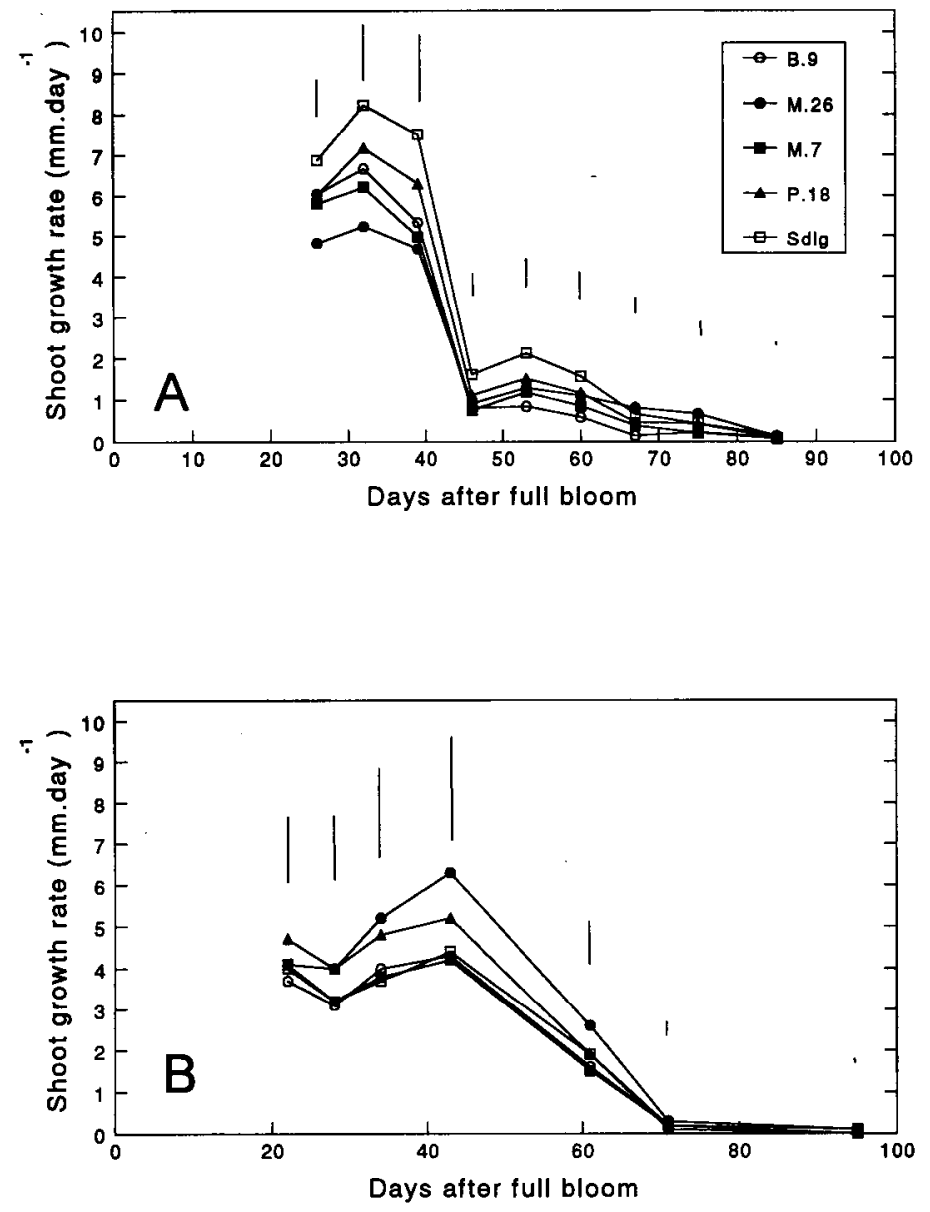

Fig. 6. Growth rate of terminal shoots of mature 'Starkspur Supreme Delicious' trees growing on 5 rootstocks. (A) 1992, full bloom $=10$ May 1992, $\mathrm{n}=50$. (B) 1993, full bloom $=6$ May 1993, $\mathrm{n}=50$. Bars indicate $\operatorname{LSD} P=0.05$.

initiation in apple is generally considered to occur within the first 40 days following bloom (Buban and Faust, 1982; Westwood, 1978) but in this study the morphological changes that result from initiation (apical doming rather than initiation itself) were measured. These morphological changes occur some unspecified time after initiation. Flower formation occurred over a period of about 20 days, and no more flowers formed after 110 DAFB. Previously, the timing of primordia formation was found to be affected by growing conditions (Fulford, 1965), but in this study the timing of flower formation was unaffected by year, despite very different conditions. For example, at the time doming was first evident, the accumulated rainfall from 1 Apr. was 172, 20, and $95 \mathrm{~mm}$ below the long term average in 1991, 1992, and 1993 respectively: Differences in the proportion of buds forming flowers also differed between rootstocks and years, but the timing of flower formation was similar across years and among rootstocks (Fig. 4 A-C).

The proportion of buds in which flowers were formed was affected by rootstock in only one of the three years of this study (1991), although similar trends were evident in 1993 (Fig. 4). The lack of more definitive differences among rootstocks is somewhat surprising since rootstock effects on flowering have been well documented (Ferree, 1976; McKenzie, 1961; NC-140, 1990). The year that rootstock differences were observed (1991) was characterized by lower rainfall and higher temperatures over the period of first appearance of doming than during the other years, suggesting a possible difference in rootstocks in their sensitivity to environmental stresses.

The moderate levels of flower formation in 1991, followed by high then low levels in 1992 and 1993 respectively, are indicative of alternate bearing, but such trends in yield per tree and yield efficiency data were only evident for trees growing on M.26 EMLA (Hirst and Ferree, 1995). In 1991, trees on M.26 EMLA rootstock produced fewer flowers than would have been expected from its field performance relative to other rootstocks reported in other studies (Hirst and Ferree, 1995; NC- 140, 199 1), which may have been due to the heavy crop borne in 1991 . This crop load may have, in turn, reduced the degree of flower formation in 1991. Barritt (1992) noted that M.26 EMLA tends to be a shallow rooted rootstock, which may also explain its relatively poor performance in a drought year. It seems unlikely that the low degree of flower formation in 1993 was due to either environmental conditions, or crop load that was only slightly higher in 1993 than in 1992

Rootstocks inducing higher degrees of tree size control also had higher SLW, also noted by Warrington et al., (1990). Buds where flower formation had occurred had larger diameters and tended to have more leaf area, and leaf dry weight per spur. Despite these trends, classifying buds as either vegetative or floral on the basis of their leaf areas or SLW was not consistently better than what was expected by chance. Bud diameters allowed the floral status' of buds to be predicted, with buds above $3.1 \mathrm{~mm}$ generally being floral, and those below $3.1 \mathrm{~mm}$ remaining vegetative. However, based on this model only $65 \%$ of buds could be correctly classified.

It is widely accepted that dwarfing rootstocks induce shoot growth cessation earlier in the season than trees growing on more vigorous rootstocks (Avery, 1969; Swarbrick, 1929), howeverthis was not found in the present study (Fig. 6b). Although we found no rootstock effect on the time of shoot growth cessation in either 1992 or 1993, a difference between these years was evident with shoot growth ceasing at 45 DAFB in 1992, and 70 DAFB in 1993. This planting was unirrigated, and the amount of rainfall (accumulated from 1 Apr.) at 40 DAFB was $106 \mathrm{~mm}$ below the long term average in 1992 compared with $40 \mathrm{~mm}$ below average in 1993. Unfavorable water relations may have induced the early and rapid termination of shoot growth observed in 1992. The cessation of shoot growth is recognized as a prerequisite for the formation of flowers (Abdulkadyrov et al., 1972; Luckwill and Whyte, 1968; Swarbrick, 1929) a finding supported by data from this study. No difference in the time of shoot growth termination among rootstocks was found in 1992 or 1993 . The time and degree of flower formation was also similar among rootstocks over this period. Furthermore earlier shoot growth termination in 1992 was associated with a much higher degree of flower formation compared with later growth cessation and lower levels of flower formation in 1993.

In summary, the course of bud development appeared to be a characteristic of the cultivar, and was not affected by rootstock. Among rootstocks differing widely in their degree of growth control and field performance, the following characteristics of flowering were constant: the time of flower formation, the type of appendages present in the bud, and the critical appendage number before doming of the apex. Rootstock did, however, demonstrate some ability to influence the proportion of buds that became floral. This work suggests that if apple producers want to alter the time of flower formation, they must use methods other than rootstock choice to achieve this.

\section{Literature Cited}

Abbott, D.L. 1970. The role of budscales in the morphogenesis of the apple fruit bud, p. 65-80. In: L.C. Luckwill and C.V. Cutting (eds.). Physiology of tree crops. Academic Press, London.

Abbott, D.L. 1977. Fruit bud formation in Cox's Orange Pippin. Rpt. Long 
Ashtoh Res. Sta. for 1976. p. 167-176.

Abdulkadyrov, S.K., S.G. Batyrkhanov, and B.R. Dzhabaev. 1972. The process of apple flower differentiation. Tr. Dagest. Skh. Jnstit. 22:58-71. Avery, D.J. 1969. Comparisons of fruiting and deblossomed maiden apple trees, and of non-fruiting trees on a dwarfing and an invigorating rootstock. New Phytol. 68:323-336.

Barritt, B.H. 1992. Intensive orchard management. Good Fruit Grower, Yakima, Wash.

Bijhouwer, J. 1924. De periodiciteit van de knopontwikkeling bij den appel (periodicity of the bud development of apple). Meded. Landb. Hoogesch. Wageningen 27(9):1-64.

Buban, T. and. M. Faust. 1982. Flower bud induction in apple trees: internal control and differentiation. Hort. Rev. 4:174-203.

Ferree, D.C. 1976. Effect of rootstocks, propagation method, and transplanting on growth and flowering of young apple trees. J. Amer. Soc. Hort. Sci. 101:676-678.

Forshey, C. 1989. Measuring the effects of growth regulators on the vegetative growth - fruiting relationship. Acta Hort. 239:211-219.

Fulford, R.M. 1965. The morphology of apple buds. I. The activity of the apical meristem. Ann. Bot. 29(113): 167-1 80.

Fulford, R.M. 1966a. The morphology of apple buds. II. The development of the bud. Ann. Bot. 30( 117):25-38.

Fulford, R.M. 1966b. The morphology of apple buds. III. The inception of flowers. Ann. Bot. 30( 118): 207-219.

Hirst, P.M. and D.C. Ferree. 1995. Rootstock effects on shoot morphology and spur quality of 'Delicious' apple and relationships with precocity and productivity. J. Amer. Soc. Hort. Sci. 120:622-634

Jones, K.M., T.B. Koen, S.J. Wilson, M. Oakford, and S.B. Longely. 1989. A reexamination of the relationship between vegetative growth and flower bud initiation in apples. Acta Hort. 239:363-366.

Luckwill, L.C. 1970. The control of growth and fruitfulness of apple trees, p. 237-254. In: L.C. Luckwill and C.V. Cutting (eds.). Physiology of tree crops. Academic Press, London.

Luckwill, L.C. 1974. A new look at the process of fruit bud formation in apple. XIX Intl. Hort. Congress, Warsaw. p. 237-245.

Luckwill, L.C. and P. Whyte. 1968. Hormones in the xylem sap of apple trees. S.C.I. Monogr. 31:87-101.

Luckwill, L.C. and J.M. Silva. 1979. The effects of daminozide and gibberellic acid on flower initiation, growth and fruiting of apple cv Golden Delicious. J. Hort. Sci. 54(3):217-223.

Maggs, D. 1955. The inception of flowering in some apple rootstock varieties. J. Hort. Sci. 30:234-241.

McKenzie, D. 1961. Rootstock-scion interaction in apples with special reference to root anatomy. J. Hort. Sci. 36:40-47.

McLaughlin, J.M. and D.W. Greene. 1991. Fruit and hormones influence flowering of apple. I. Effect of cultivar. J. Amer. Soc. Hort. Sci. 116:446-449.

Micklem, T. 1938. Studies on fruit bud formation in deciduous fruit trees in South. Africa. J. Pomol. Hort. Sci. 16:201-209.

Minitab, Inc. 1993. Minitab reference manual. Release 9 for Windows. Minitab Inc., State College, Pa.

NC-140. 1990. Early performance of 'Starkspur Supreme Delicious' on 16 rootstocks in the NC-140 cooperative planting. Fruit Var. J. 44(4): 225-235.

NC-140. 1991. Performance of 'Starkspur Supreme Delicious' apple on 9 rootstocks over 10 years in the NC- 140 cooperative planting. Fruit Var. J. 45(4):192-199.

Swarbrick, T. 1929. Factors governing fruit bud formation. VIII. The seasonal elongation growth of apple varieties on some vegetative rootstocks, and its possible relation to fruit bud formation. J. Pomol. $7: 100-129$.

Volz, R.K. and J.N. Knight. 1986. The use of growth regulators to increase precocity in apple trees. J. Hort. Sci. 61(2):181-189.

Warrington, I.J., D.C. Ferree, J.R. Schupp, F.G.J. Dennis, and T.A. Baugher. 1990. Strain and rootstock effects on spur characteristics and yield of 'Delicious' apple strains. J. Amer. Soc. Hort. Sci. 115:348-356. Westwood, M.N. 1978. Temperate zone pomology. Freeman, San Francisco. 